\title{
Cervico-Oculo-Acoustic Syndrome in a Male with Consanguineous Parents
}

\author{
L. Di Maio, V. Marcelli, C. Vitale, M. Menzione, A. De Giorgio, F. Briganti, \\ A. Perretti, E. Marciano, A. Filla, G. De Michele
}

\begin{abstract}
Background: The cervico-oculo-acoustic syndrome comprises Klippel-Feil anomaly, sensorineural deafness and Duane's retraction syndrome. Polygenic, autosomal dominant, and X-linked inheritance have been hypothesized. The disorder has rarely been reported in males. Case Report: A 42-year-old male, born of consanguineous parents, presented with Duane's syndrome, mixed hearing loss, C2-C3 fusion, neck stiffness, and right facial palsy. A variety of cardiac, neurological and urogenital anomalies occurred in his relatives. The electro-oculographic studies showed impaired abduction and adduction of the right eye and impaired abduction of the left eye. Vergence, vertical eye movements and peripheral vestibular responses were normal. Somatosensory evoked potentials showed absence of the N13 peak and brainstem auditory evoked potentials bilateral delay of the I-III interpeak latencies. Conclusions: Consanguinity of the patient's parents, not previously reported, suggests autosomal recessive inheritance, but autosomal dominant inheritance is indicated by the family history. The pattern of the oculomotor deficit is consistent with bilateral dysplasia of the abducens nuclei with preserved internuclear neurons in the right abducens nucleus. Neurophysiological investigations revealed lower brainstem and cervical cord involvement.
\end{abstract}

RÉSUMÉ: Syndrome cervico-oculo-acoustique chez un homme issu d'une union consanguine. Contexte: Le syndrome cervico-oculo-acoustique comprend le syndrome de Klippel-Feil, une surdité de perception et le syndrome de rétraction du globe oculaire de Duane. Plusieurs modes d'hérédité ont été proposés, soit une hérédité polygénique, dominante autosomique ou liée à l'X. Ce syndrome a rarement été rapporté chez un homme. Observation: Un homme de 42 ans, issu d'une union consanguine, a consulté pour un syndrome de Duane, une surdité mixte, une fusion de C2-C3, une raideur cervicale et une paralysie faciale. À l'histoire familiale, on notait la présence de plusieurs anomalies cardiaques, neurologiques et urogénitales dans sa parenté. Les études électro-oculographiques ont montré une abduction et une adduction anormales au niveau de l'œil droit et une abduction anormale au niveau de l'œil gauche. La convergence, les mouvements oculaires verticaux et les réponses vestibulaires périphériques étaient normales. Les potentiels évoqués somato-sensitifs ont révélé une absence du pic N13 et les potentiels évoqués du tronc cérébral ont montré un retard bilatéral des intervalles inter-pics I-III. Conclusions: La consanguinité chez les parents de notre patient, qui n'a jamais fait l'objet d'une publication, suggère une hérédité récessive, sans exclure la possibilité d'une hérédité dominante autosomique à cause de 1'histoire familiale. Le type de déficit oculomoteur observé chez ce patient est compatible avec une dysplasie bilatérale du noyau du nerf moteur oculaire externe avec préservation des neurones internucléaires du noyau du nerf moteur oculaire externe droit. Les études neurophysiologiques ont révélé qu'il existait des anomalies à la région inférieure du tronc cérébral et à la moelle épinière.

Can. J. Neurol. Sci. 2006; 33: 237-239

The cervico-oculo-acoustic syndrome (COAS, MIM 314600 ), described by Wildervanck ${ }^{1}$ in 1952 , consists of Klippel-Feil anomaly (congenital fusion of cervical vertebrae), congenital sensorineural deafness, and Duane's syndrome. Duane's syndrome is a congenital ocular motility disorder characterized by absent or limited abduction or adduction or both. The palpebral fissure narrows (retractio bulbi) on attempted adduction. $^{2}$ The disorder has been reported rarely in males and polygenic inheritance with limitation to females has been suggested. ${ }^{1,3}$ We report the case of a 42-year-old man with COAS, who was born of consanguineous parents.

\section{CASE RePORT}

A 42-year-old man was admitted for vision disturbances, head motility impairment, limb paresthesias, and trouble in balancing. He was a farmer and while driving his tractor he had to turn his body to view behind him because of difficulty turning his eyes and head. He complained of tingling in all four limbs from the previous six months and abnormal tearing from his right eye or both eyes when eating. 
He was the second of three siblings. His parents were first cousins (Figure 1). His father (I-1) had been diagnosed as a carrier for asymptomatic transposition of the great arteries. A brother (II-1) had mental retardation and seizures and died at the age of 25 years. The youngest brother was normal. The patient had two children. One child (III-1) was treated for bilateral congenital inguinal herniation and the other (III-2) was affected by pseudohermaphroditism.

Physical examination showed a stocky, vigorous man, with a height of $159 \mathrm{~cm}$, weight of $85 \mathrm{~kg}$, and head circumference of $61 \mathrm{~cm}$. He had a low posterior hairline, short neck, broad square nose with a flat bridge, clinodactily of the fifth finger, and pes cavus. Visual acuity was 20/35 RE and 20/20 LE. Fundi, ocular media, pupils and visual fields were normal. Abduction and adduction of the right eye and abduction of the left eye were impaired (Figure 2). Adduction of the left eye was associated with retraction of the globe and narrowing of the palpebral fissure. There was no deviation in primary position nor diplopia in any gaze position. Vergence, vertical saccades, vertical smooth pursuit, and vertical and torsional vestibular eye movements were normal. The patient also had right facial palsy, marked neck stiffness and normal tendon reflexes. There was no muscle atrophy, fasciculations, sensory loss, or signs of cerebellar dysfunction. Plantar reflexes were flexor bilaterally.

Electro-oculography with bilateral monocular electrodes confirmed the abnormalities of horizontal eye movement noted on physical examination. During rightward gaze, there was gaze-evoked nystagmus of the left eye. Vergence and vertical eye movements were normal. Irrigation of the left ear with warm water $\left(44^{\circ} \mathrm{C}\right)$ and irrigation of the right ear with cold water $\left(30^{\circ} \mathrm{C}\right)$ induced tonic deviation of the left eye to the right. Pure tone audiometry showed bilateral moderate conductive hearing loss and normal bone conduction except at $2 \mathrm{KHz}$ (Figure 3). Tympanometry showed normal acoustic impedance and bilateral absence of acoustic reflexes.

Spinal X-ray revealed fusion of C2-C3 vertebrae, compatible with type 2 Klippel Feil anomaly. Brain MRI, electroencephalogram, electrocardiogram, echocardiogram, chest X-ray, and renal and urinary tract ecography were normal.

Conduction velocities of the right ulnar, left deep peroneal, and left sural nerve were normal. There was a slight reduction of the sensory velocity $(43.5 \mathrm{~m} / \mathrm{sec})$ of the right median at the wrist, consistent with a

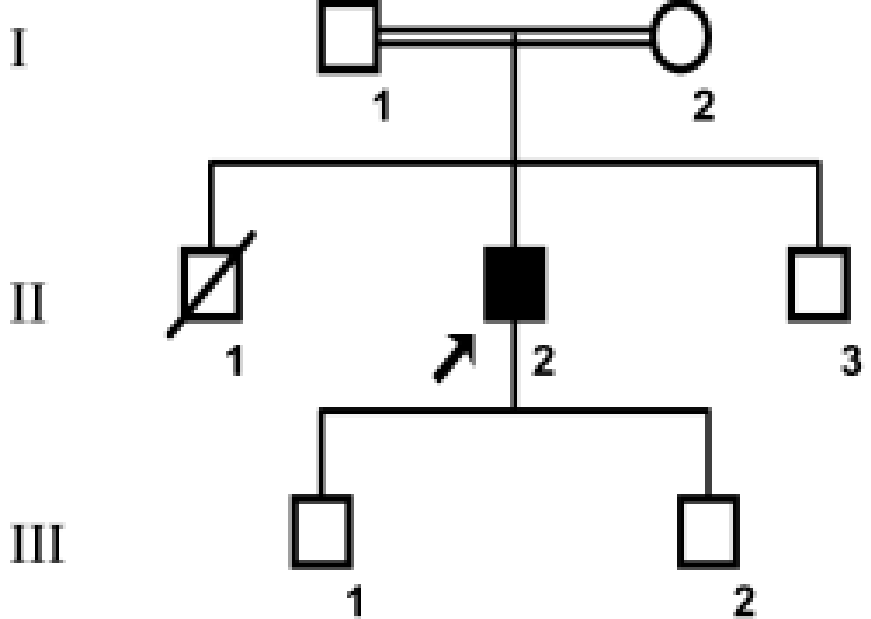

Figure 1: The parents of the proband are first cousins. The father (I:1) is affected with transposition of the great arteries. One brother (II:1), affected with mental retardation and seizures, died at the age of 25 years. One offspring (III:1) is affected with congenital inguinal herniation and the other (III:2) with pseudohermaphroditism.

carpal tunnel syndrome. Somatic sensory evoked testing, performed using median nerve stimulation at the wrist, showed normal Erb's potential and P14, N18, and N20 peak latencies, whereas N13 peak was absent. Brainstem auditory evoked potentials demonstrated bilaterally delayed I-III interpeak latencies.

\section{Discussion}

The mode of inheritance of COAS is not clearly established. Although in most case reports family history has been negative, a variety of anomalies have been described in close relatives (congenital deafness, heterochromia, rachischisis, hydrocephalus, epilepsy, clubfoot, short neck, anencephaly, Duane's syndrome). ${ }^{1}$ Reports of males affected by COAS are scanty and

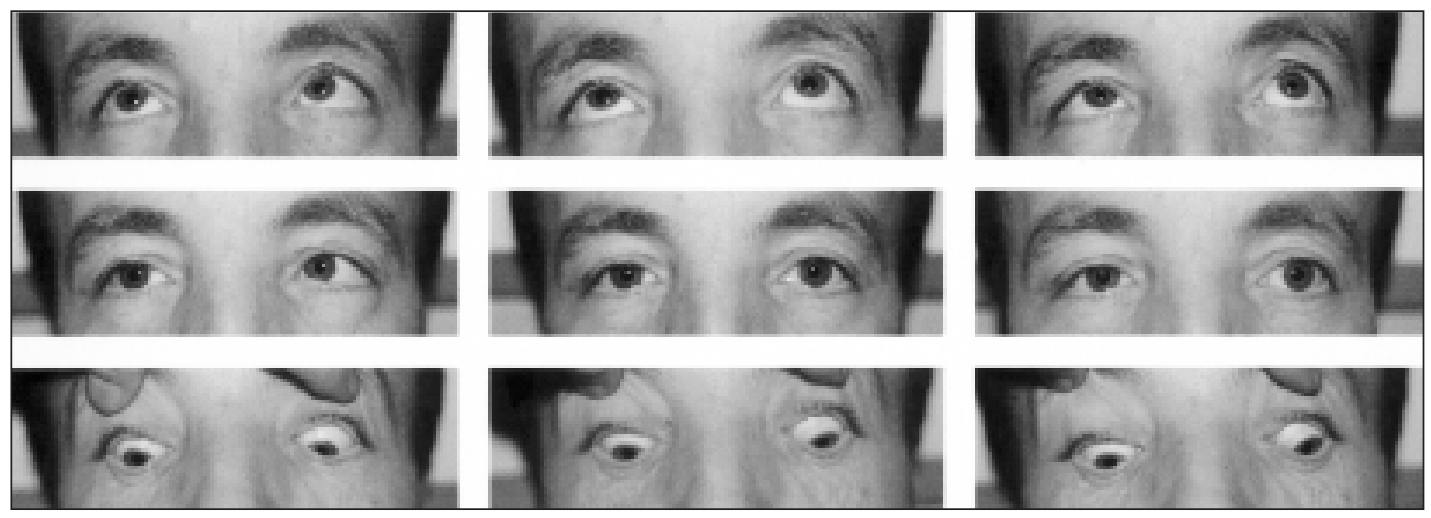

Figure 2: Primary position of the eyes (centre), attempts to look on the right, on the left, upward and downward. Impaired right eye abduction and adduction and left eye abduction are evident. Narrowing of the right palpebral fissure in primary position is due to mild orbicularis spasm resulting from previous facial nerve palsy. 


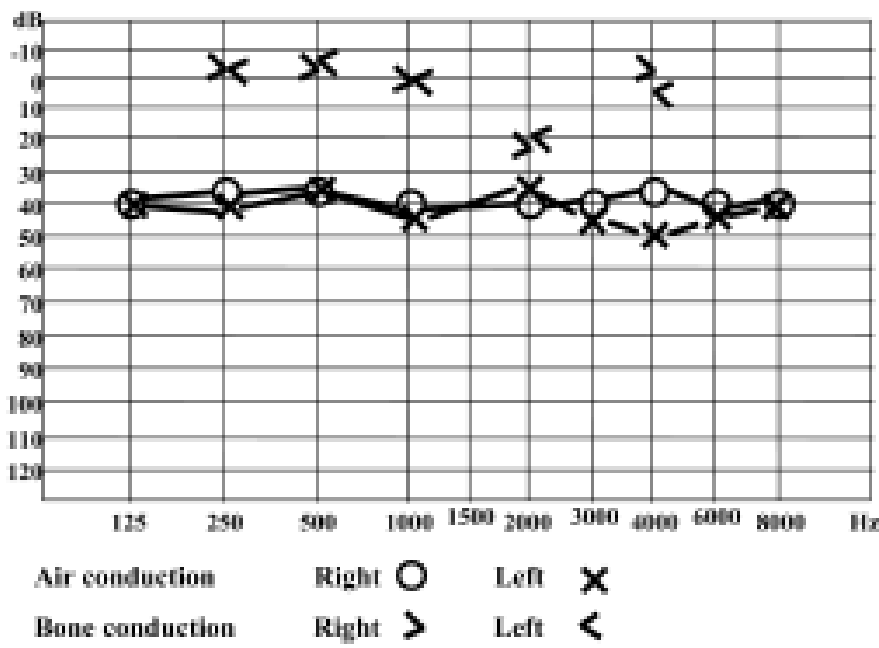

Figure 3: Audiogram of the patient.

a tenfold female prevalence was reported by Wildervanck. ${ }^{1}$ Polygenic heredity with sex limitation to the female, autosomal dominant inheritance with incomplete penetrance and variable expressivity, and X-linked inheritance with lethality in hemizygous males have been postulated. In the case reported here, the family history of mental retardation and cardiac and urogenital malformations is suggestive of autosomal dominant transmission. However, ours is the first report of parental consanguinity with COAS and provides support for an autosomal recessive mode of inheritance.

The occurrence of the complete triad of bilateral impairment of eye abduction, fused cervical vertebrae and sensorineural hearing loss is pathognomonic of COAS. Often, however, the syndrome is incomplete and there is clinical variability. Our patient had associated neck stiffness, facial paralysis and limb paresthesias, which have been reported previously.4,5 Rarely, mixed hearing loss has been reported due to anomalies of the ossicular chain. ${ }^{6}$ In our patient, pure tone audiometry and impedance analysis showed mixed hearing loss reminiscent of otosclerosis. There are also rare reports of associated brainstem and cerebellar hypoplasia and other brain and spinal cord abnormalities. ${ }^{7,8}$ Brain MRI was normal in our patient but the electrophysiological findings of prolonged brainstem-evoked IIII interpeak latencies and absent somatosensory-evoked N13 peak suggest involvement of the lower brainstem and cervical spinal cord.

Duane's syndrome is bilateral in about $20 \%$ of cases. ${ }^{2}$ Autopsy specimens have shown absence or hypoplasia of the abducens motor neurons and nerve..$^{9-13}$ Familial occurrence has been mentioned, but it is sporadic in most cases. Duane's syndrome is traditionally classified into 3 types: type 1 (limited abduction), type 2 (limited adduction), and type 3 (limited abduction and adduction). However, many cases do not fit into the above patterns. Our patient's deficit of abduction and adduction of the right eye and abduction of the left eye may be classified as a Duane's syndrome type 3 on the right and type 1 on the left. This pattern of deficit may be due to loss of motor neurons in the right abducens nucleus and loss of both motor and internuclear neurons (projecting to right medial rectus motor neurons) in the left abducens nucleus. ${ }^{14}$ Marked difficulty in eye and head version was a prominent complaint of our patient. The association of neck stiffness and eye movement limitation aggravated the difficulty in lateral viewing.

\section{REFERENCES}

1. Wildervanck LS. The cervico-oculo-acusticus syndrome. In: Vinken PJ, Bruyn GW, Myrianthopoulos NC, editors. Handbook of Clinical Neurology, vol 32. Amsterdam: North Holland Publishing Company; 1978: p.123-30.

2. Gutowski NJ. Duane's syndrome. Eur J Neurol. 2000; 7: 145-9.

3. Online Mendelian Inheritance in Man, OMIM (TM). Johns Hopkins University, Baltimore, MD. MIM Number: 314600: 7/2/2004: World Wide Web URL: http://www.ncbi.nlm.nih.gov/omim/.

4. Hughes PJ, Davies PTG, Roche SW, Matthews TD, Lane RJM. Wildervanck or cervico-oculo-acoustic syndrome and MRI findings. J Neurol Neurosurg Psychiatry. 1991; 54: 503-4.

5. Johnson NA, McClure MJ, Protzko E, Fosmire D. Case report: Wildervanck's syndrome presenting as hemiparesthesia. Mil Medicine. 1995; 160: 208-11.

6. Cremers CW, Hoogland GA, Kuypers W. Hearing loss in the cervico-oculo-acoustic (Wildervanck) syndrome. Arch Otolaryngol. 1984; 110: 54-7.

7. Balci S, Oguz KK, Firat MM, Boduroglu K. Cervical diastematomyelia in cervico-oculo-acoustic (Wildervanck) syndrome: MRI findings. Clin Dysmorphol. 2002; 11: 125-8.

8. Brodsky MC, Fray KJ. Brainstem hypoplasia in the Wildervanck (cervico-oculo-acoustic) syndrome. Arch Ophthalmol. 1998; 116: 383-5.

9. Matteucci P. I difetti congeniti di abduzione con particolare riguardo alla patogenesi. Rassegna Ital Oftalmol. 1946; 15: 345-80.

10. Hotchkiss MG, Miller NR, Clark AW, Green WR. Bilateral Duane's retraction syndrome. A clinical-pathologic case report. Arch Ophthalmol. 1980; 98: 870-4.

11. Miller NR, Kiel SM, Green WR, Clark AW. Unilateral Duane's retraction syndrome (type 1). Arch Ophthalmol. 1982; 100: 1468-72.

12. Hickey WF, Wagoner MD. Bilateral congenital absence of the abducens nerve. Virchows Arch A Pathol Anat Histopathol. 1983; 402: 91-8.

13. Mulhern M, Keohane C, O'Connor G. Bilateral abducens nerve lesions in unilateral type 3 Duane's retraction syndrome. Br J Ophthalmol 1994; 78: 588-591.

14. Leigh JR, Zee DS. The neurology of eye movement. Contemporary Neurology Series, 3rd ed. New York: Oxford University Press, 1999: 216. 